\title{
Mental health-promoting dialogues from the perspective of community-dwelling seniors with multimorbidity
}

This article was published in the following Dove Press journal:

Journal of Multidisciplinary Healthcare

28 April 2014

Number of times this article has been viewed

\author{
Åke Grundberg' \\ Britt Ebbeskog ${ }^{2}$ \\ Sanna Aila Gustafsson ${ }^{3}$ \\ Dorota Religa' \\ 'Division of Neurogeriatrics, \\ ${ }^{2}$ Division of Nursing, Department \\ of Neurobiology, Care Sciences \\ and Society, Karolinska Institutet, \\ Stockholm, ${ }^{3}$ Psychiatric Research \\ Centre, School of Health and Medical \\ Sciences, Örebro University, Örebro, \\ Sweden
}

Correspondence: Åke Grundberg Division of Neurogeriatrics, Department of Neurobiology, Care Sciences and Society, Karolinska Institutet, |4| 86 Stockholm, Sweden Email ake.grundberg@ki.se

\begin{abstract}
Mental health promotion needs to be studied more deeply within the context of primary care, because persons with multiple chronic conditions are at risk of developing poor mental health. In order to make progress in the understanding of mental health promotion, the aim of this study was to describe the experiences of health-promoting dialogues from the perspective of community-dwelling seniors with multimorbidity - what these seniors believe is important for achieving a dialogue that may promote their mental health. Seven interviews with six women and one man, aged 83-96 years, were analyzed using qualitative content analysis. The results were summarized into nine subcategories and three categories. The underlying meaning of the text was formulated into an overarching theme that embraced every category, "perceived and well-managed as a unique individual". These seniors with multimorbidity missed someone to talk to about their mental health, and needed partners that were accessible for health dialogues that could promote mental health. The participants missed friends and relatives to talk to and they (crucially) lacked health care or social service providers for health-promoting dialogues that may promote mental health. An optimal level of care can be achieved through involvement, continuity, and by providing a health-promoting dialogue based on seniors' needs and wishes, with the remembrance that general health promotion also may promote mental health. Implications for clinical practice and further research are discussed.
\end{abstract}

Keywords: aged, care of older people, mental health-promotion, municipal care

\section{Introduction}

The prevalence of mental disorders increases with age. ${ }^{1}$ Poor mental health has become a major public health issue among older people in Sweden, ${ }^{2}$ and there are similar issues in other high-income countries. ${ }^{3}$ Mental disorders may involve anxiety or depression, can lead to multiple prescriptions of pharmaceuticals (for different mental disorders), social isolation, and suicidal behavior. ${ }^{1}$ Seniors with multimorbidity (ie, patients with more than one long-term condition) are common in several Western countries, both in the general population and among primary care patients. ${ }^{4}$ Mental health promotion needs to be studied more deeply within the context of primary care, because persons with multiple chronic conditions are at risk of developing poor mental health. ${ }^{5}$

Mental health promotion is defined by the World Health Organization as "the creation of living conditions and environments that support mental health and allow people to adopt and maintain healthy lifestyles". ${ }^{6}$ In many ways, promotion of mental health also overlaps with prevention, yet they are also distinct, in that the emphasis in mental health promotion is on positive mental health. ${ }^{7}$ Still, a lot could be done to promote mental health among seniors. For instance, mental health promotion could 
focus on determinants such as: social relations, the awareness of mental health issues, and the availability of therapeutic and psychosocial interventions, like practical support, structured individual counseling, and consistent, long-term, professional support. ${ }^{8}$ Mental health is also determined by multiple and interacting psychological, social, and biological factors; just as illness and health are in general. ${ }^{6}$ Mental health and physical health are also closely associated through various mechanisms, as shown by studies of the links between depression and cardiovascular disease. ${ }^{6}$ The World Health Organization declared: "most preventive health care and screening for early disease detection and management takes place in the primary health care setting at the community level". ${ }^{9}$ Furthermore, prevention of late-life depression requires identification of seniors at highest risk, such as those with specific chronic medical conditions, ${ }^{10}$ painful physical symptoms, ${ }^{11}$ and perceived loneliness. ${ }^{12}$ Nevertheless, promoting good health and minimizing the consequences of chronic disease through early detection has become a major focus for primary care, ${ }^{3}$ given that primary care professionals often encounter seniors with multimorbidity. ${ }^{13}$

In Sweden, seniors with multiple chronic conditions often live in the community; their homes play a primary role as healthpromoting arenas for health care and social service providers. In Swedish primary care, general practitioners and specially-trained nurses, called district nurses, have the main responsibility for health promotion activities. Their responsibilities are stipulated by law and include health promotion among patients of all ages. ${ }^{14}$ One example of a health promotion activity is what is commonly referred to as a "preventive home visit"15 - an integral aspect of primary care. ${ }^{16}$ Swedish district nurses provide preventive home visits, to all 75 -year-old persons who agree to it. ${ }^{17}$ Preventive home visits is a free of charge planned contact that offers a senior the opportunity to discuss her/his health and health problems in a structured way. ${ }^{17}$ District nurses in primary care ${ }^{14}$ provide health care to an elderly population in their own homes, with support from municipal home help services, which supports autonomy, by enabling the elderly to stay in their own housing as long as possible. ${ }^{12}$ Seniors living in their own homes can also be granted support from the municipal home help service, in accordance with the Social Service Act. ${ }^{18}$ The support varies according to the client's need, ${ }^{19}$ and facilitates daily life in areas such as purchasing groceries, cleaning, and personal care. The district nurse may delegate the responsibility for administration of prescribed medication to an appropriately-qualified social service provider from the municipal home help service. However, fragmentation of care for community-dwelling seniors with multimorbidity occurs. For many years, increased collaboration between social service and medical providers has been proposed. ${ }^{20}$ Further, a holistic approach and preserved continuity of care and support are required to help these seniors to retain their quality of life and remain in their homes without too many interruptions from acute hospital care. ${ }^{21}$

Our previous study ${ }^{22}$ showed that social contacts, physical activity, and optimism may improve mental health, while social isolation, aging, and chronic pain may worsen it. Furthermore, mental health was described mostly in negative terms, and as something that one could not discuss with others. Other informants perceived their own experiences of mental illness (such as depression) as "normal" and a "natural" part of the aging process. ${ }^{22}$ These assumptions of depression in older age have to be corrected when effective psychological and medical treatments are available. ${ }^{23}$ In order to make progress in understanding mental health promotion, the aim of this study was to describe the experiences of health-promoting dialogues from the perspective of community-dwelling seniors with multimorbidity, and what these seniors believe to be important for achieving a dialogue that may promote their mental health.

\section{Methods}

The study used a qualitative descriptive design, with a latent and manifest qualitative content analysis technique inspired by Graneheim and Lundman. ${ }^{24}$ Qualitative interviews were used for data collection, which gave the researcher the opportunity to understand the participant's lived world, from the subject's own experiences and unique perspective. ${ }^{25}$ Content analysis is a method that facilitates description of the content of communication, by measuring the intensity or frequency of occurrence of phrases, words, or sentences. ${ }^{26}$ We wanted to capture meaning in the communication of narrative data. An inductive ${ }^{24}$ content analysis of the qualitative data was chosen, according to the purpose of this study, and because there are, to our knowledge, no previously-identified studies dealing with the phenomenon (ie, experiences of health dialogues and dialogues that may promote mental health). For this study, we chose both manifest (what the text said) and latent (what the text is talking about) content analysis, ${ }^{24,26}$ in order to further study our earlier finding: that participants had difficulties talking about their mental health. ${ }^{22}$

\section{Participants}

A convenience and purposeful sample ${ }^{27}$ of seven seniors participated in this study: six women (aged 83-96 years old) and one man (aged 85 years old), living in their own homes in a suburb of Stockholm. All participants were widowed. 
The six women lived alone, while the man lived with his son. The seniors had agreed earlier to participate in this follow-up study, since they previously participated in a study with 13 former inpatients of a geriatric clinic specializing in elderly people with multimorbidity. ${ }^{22}$ Criteria for exclusion comprised: 1) being diagnosed or suspected of having dementia; and 2) not speaking the local language (Swedish). Three former participants had died, and two had developed what was suspected to be dementia, and then moved to a nursing home, excluding them from this study. Eight of the former 13 participants were contacted by the first author. One of those seniors refused to participate, and seven agreed to participate in an interview, which took place in the senior's home.

\section{Procedure}

The first author contacted the participating seniors at their homes, where the interviews took place, performed by the first author. A semi-structured, in-depth interview was chosen, to extend our understanding of dialogues that could promote mental health. All individual interviews began with a question about the seniors' experiences of health-promoting dialogues, as to what they perceived was important in dialogues that could promote their mental health. Follow-up and probing questions were used, in order to know more about how their experiences of dialogues had a positive impact on their mental health, and about what they regarded as important social contacts that had improved their mental health or could promote it through dialogues. The credibility of data collection was confirmed by a member check technique: ${ }^{28}$ at the end of each interview, the interviewer made a summary of the content and asked if the expressed meaning had been captured and comprehended. The interviews (45-65 minutes) were conducted in the form of a conversation. Data were collected from February to June 2011.

\section{Data analysis}

The transcribed text was analyzed using content analysis inspired by Graneheim and Lundman. ${ }^{24}$ The audiotaped interviews were transcribed verbatim by the first author, who read all texts thoroughly, several times, to get an overall picture of the data. The texts were then structured into two domains, based on the two aims of the interview schedule: 1) experiences of health-promoting dialogues, and 2) what is important in dialogues that could promote mental health. The interview text was further divided into meaning units: words and statements that were related to the same central meaning. These condensed meaning units were shortened in length, and in order to be close to the text. Each meaning unit was then labeled with a code, and categorized inductively (on the basis of the content before the whole text was condensed and labeled with codes). Since the informants expressed that they were not aware of any health or mental health-promoting dialogues with health professionals, the two domains were put together into one unit of analysis, based on what is important for a general dialogue that could promote mental health. The codes in the whole unit of analysis were further compared for differences and similarities, and were sorted into categories, based on similarities. In this comparison, three categories emerged, which were then finally sorted into nine subcategories (ie, three subcategories for each of the three categories). A category refers mainly to a descriptive level of content. It can be seen as an expression of the manifest content of the text, and may answer the question, "What?". ${ }^{24}$ The process of analysis involved back-and-forth movements between the whole text, the codes, and the categories, for one or several themes. A theme can be seen as an expression of the latent content of the text, and may answer the question, "How?". ${ }^{24}$ This process was repeated, and, as a final step, one overarching theme was formulated, which captured the participants' experiences of dialogues that could promote mental health, and what they believed was important for achieving a dialogue that could promote their mental health. To enhance trustworthiness, the codes, categories, subcategories, and theme were reflected upon and discussed by the research team throughout the analysis process, resulting in consolidation of the findings.

\section{Findings}

As the result of the analysis of the interviews, nine subcategories, three categories, and one theme were identified. The underlying meaning (ie, the latent content) of the text was formulated into an overarching theme that embraced every category: "Perceived and well-managed as a unique individual". The category "Accessibility for dialogue" contained aspects of a person, time, and forum for dialogues that could promote mental health. The category "Meeting a competent person" contained professional, social, and personal aspects. The category "Getting social support" contained informative, instrumental, and emotional aspects. For illustration of the analysis, with examples of codes and emerged subcategories, categories, and overarching theme, see Table 1.

\section{Accessibility for dialogue}

This category was divided into aspects of a person, time, and forum for perceived and preferred dialogues with 
Table I Examples of codes and emerged subcategories, categories, and theme from the content analysis

\begin{tabular}{|c|c|c|c|c|c|c|c|c|c|}
\hline \multicolumn{5}{|l|}{ Theme } & \multicolumn{5}{|c|}{ Perceived and well-managed as a unique individual } \\
\hline \multicolumn{2}{|l|}{ Category } & \multicolumn{3}{|c|}{ Accessibility for dialogue } & \multicolumn{3}{|c|}{ Meeting a competent person } & \multicolumn{2}{|c|}{ Social support } \\
\hline Subcategory & $\begin{array}{l}\text { Someone } \\
\text { for dialogue }\end{array}$ & $\begin{array}{l}\text { Time for } \\
\text { dialogue }\end{array}$ & $\begin{array}{l}\text { Forum for } \\
\text { dialogue }\end{array}$ & $\begin{array}{l}\text { Professional } \\
\text { knowledge }\end{array}$ & $\begin{array}{l}\text { Social } \\
\text { skills }\end{array}$ & $\begin{array}{l}\text { Personality } \\
\text { traits }\end{array}$ & $\begin{array}{l}\text { Informative } \\
\text { support }\end{array}$ & $\begin{array}{l}\text { Instrumental } \\
\text { support }\end{array}$ & $\begin{array}{l}\text { Emotional } \\
\text { support }\end{array}$ \\
\hline $\begin{array}{l}\text { Examples } \\
\text { of codes }\end{array}$ & $\begin{array}{l}\text { Being } \\
\text { present }\end{array}$ & $\begin{array}{l}\text { Providing } \\
\text { dialogue }\end{array}$ & $\begin{array}{l}\text { Personal } \\
\text { meetings }\end{array}$ & $\begin{array}{l}\text { Caring } \\
\text { purpose }\end{array}$ & $\begin{array}{l}\text { Being } \\
\text { firm }\end{array}$ & $\begin{array}{l}\text { Being } \\
\text { natural }\end{array}$ & Learning & $\begin{array}{l}\text { Practical } \\
\text { help }\end{array}$ & $\begin{array}{l}\text { Improving } \\
\text { mood }\end{array}$ \\
\hline
\end{tabular}

friends, neighbors, relatives, and different care or health care professionals who could help the informants promote their mental health. First of all, the participating seniors had difficulties expressing whether they had any experiences of pronounced and purposeful health-promoting dialogues with any health care professional. Further, all seniors reported that they were missing "a person for dialogue" about their general health and mental health. This desire included contacts with district nurses, general practitioners, counselors, priests, physiotherapists, and personnel from home help services. One female said: "I wish that there was anyone from the health care system that one, in a way, [...] could meet to sit down with and to talk". Even relatives, such as daughters, may help promote mental health. Another participant said: "I feel more relaxed in the body and so [...] when I talk with my relatives! And so you may get a better sleep". The seniors also reported that district nurses had less time for dialogue or a general conversation about the seniors' health. According to the participants, district nurses were occupied with activities such as medical assignments, taking venous blood samples, or measuring blood pressure in the seniors' homes. Another man reported that he often met different general practitioners and district nurses at the health center. He further noted that "the health center isn't for us" and that he couldn't talk with anyone at the health center about his mental health. There were also seniors who reported that they could talk about almost anything with their specific district nurse and general practitioner. The participants in this study had contacts with several persons from home help services, whom they didn't know by name. One man said that he could talk with several contacts from home help services about his mental health. However, other participants reported that personnel from home help services didn't have the time for a conversation. One participant said: "And then there is the home help services [...] they are only entering my home and then turn around and leave". Another female said:

Well $[\ldots]$ yes, and so they [personnel from home help services] also always are in a hurry all the time [...] They never have the time to stay for a while [...] Yes, and that means that I only have a few minutes to talk about how I feel.

It was seen as important to have a more frequent contact for general conversations with their friends, neighbors, children, or grandchildren. However, most participants' friends had died, had developed cognitive impairment, or had multiple chronic conditions affecting their physical health and mobility so that they had difficulties leaving their homes and visiting the participants. It was important that a social contact was present in the meeting who had a personal interest and desire to talk about mental health. The aspect of time for health dialogue indicated the importance of health care professionals providing a dialogue and reserved time for this purpose. Furthermore, it was important that these social contacts weren't in a hurry, stressed, or occupied with other activities at the same time. The aspect of a "Forum for dialogue" described where preferably the dialogue should take place, such as in the senior's home, hospital, or at the health center. There were seniors who preferred personal meetings for mental health dialogue in their homes. Other participants had personal experiences from contacts with health care professionals via telephone - which was described as an acceptable way to discuss mental health. The telephone was further described as an important device in breaking social isolation and feelings of loneliness, through daily contacts with children or friends. As one participant said:
Yes, I had a lot of telephone contact with a friend $[\ldots]$ and then we used to talk about things that had happened to us that day $[. .$.$] She was very sharp in the head and we used$ to analyze things!

Other seniors talked about a desirable environment for personal meetings in terms of a "peaceful" and "quiet" place, not crowded with people, where they could sit down without feeling stressed during a dialogue about mental health: "Because I have a difficult time when I am around a lot of people, I used to become dizzy in my head". One other woman reported: "Yeah, that one sits down in a quiet 
place and that the person you speak to is calm so that you also become calm".

\section{Meeting a competent person}

This category was divided into professional, social, and personal aspects. The category included perceived and desirable competencies among persons with whom participants wished to have a mental health dialogue, according to their experiences of dialogues with other social contacts that had promoted or could promote their health. The professional aspect of competence meant a desire to talk with health care professionals prepared for dialogues about mental health. "Professional knowledge" meant desirable fundamental knowledge and skills, in a position or occupation, which was expressed in terms of being versed and educated in the mental health field. As one participant said:

The person had to be educated, so to speak [...] and she [a nursing aide at a senior daycare] was probably very educated for the mental thing.

Other seniors mentioned competence in communicating in Swedish, as well as in general verbal communication. It was also important that health care and other care professionals had a caring purpose when they visit seniors' homes. Such contacts for dialogues were specific persons from home help services, district nurses, general practitioners, and a priest. "Social skills" meant desirable social competencies among any social contacts, and their ability to cooperate with the senior. Further, any social contacts had to be firmly trusted, committed, and interested in talking about the seniors' mental health. One woman reported her experiences of talking to various personnel from home help services who had not shown that they really cared about her, and who performed their job assignments in a "mechanical" way. It was also important that a social contact was able to listen, showed sympathy, and wasn't bored during the conversation. Furthermore, the participants wanted the contact to understand what they talked about when they described how they felt and how they were doing. One woman said: "It is important that the person understand this [...] who understands those who have mental health problems, so to speak". She further described her own experiences of such personal contact:

She [a nursing aide at a senior daycare] had something special about herself, which made me [...] she understands a lot, thus, how it was $[\ldots]$ to be lonely and such thing $[\ldots]$ Well, you can almost tell when you look at her that she isn't like other people [...] you feel confident as soon as you look at her!

It was important to know a person well in order to talk about emotions. One participant said:

One has to $[\ldots]$ sort of, learn to know the person so one knows what one can $[\ldots]$ what one can $[\ldots]$ so one doesn't have to choose the words but lets it come from the heart, directly in this way.

Another woman repeatedly expressed the importance of knowing a person well for a mental health dialogue: "I never go in to any deep dialogues with people that I don't know". It was also important that social contacts for mental health dialogues showed their own feelings when they asked questions about the seniors' mental health, that the dialogue itself was, furthermore, about "give and take", and that the contact took an active part in whatever subjects the seniors chose to talk about. There were also participants who mentioned confidence (eg, that they had to be certain that the content of the mental health dialogue wasn't spread to other people). The personal aspect of competence, "Personality traits", meant a desirable personal competencies and approaches among any social contacts. Furthermore, a social contact should take initiative for a dialogue, and then be "accurate", "honest", "helpful", and "show patience" when he or she talks about the senior's mental health. One female said that she was missing her dialogues with a former nursing aide at the daycare center: "She was so gentle and she was, yes, she was so marvelous, that human being!". Furthermore, the social contact should be "happy", "funny", "humorous", and able to "make a joke" to defuse undesirable emotions that may occur during or after a mental health dialogue. The seniors also mentioned more diffuse personal qualities that were described in terms of being "natural", "human", "stable", and "sweet". There were also seniors who indicated that contacts for mental health dialogues should not be "too young" and should have enough experience of talking to other persons with mental health problems. Furthermore, it was important that they had "life experience" and had developed "general knowledge", so that they were able to talk about whatever subjects the senior chose to talk about. One woman said that it was important that health care professionals only asked her how she was doing if they were able to "handle" her answer, which demanded probing questions about her anxiety and the fact that she had felt depressed for a long time during her adult life. 


\section{Getting social support}

This category was divided into informative, instrumental, and emotional aspects. The category included perceived and desirable social support. This support could be received from relatives, neighbors, district nurses, general practitioners, counselors, priests, physiotherapists, nursing aides, or other personnel from home help services. The informative aspect of social support meant information, learning, and guidance to increase the seniors' knowledge about their general health, mental health, and diseases. This "informative support" should result from follow-up questions to evaluate the participants' experiences of the aging process itself, general conditions, or well-being, along with their symptoms and medical treatments for current diseases. It was important that somebody evaluate their perceived health, and one woman thought that health dialogues should mean that somebody initially said "hello" and asked her how she was doing today. The most desirable content in a mental health dialogue was about the seniors' individual experiences of how they were doing and feeling, risk factors of mental health, and how mental health may be promoted. Furthermore, one participating senior said that personal dialogue had been important to learn how she would promote her health:

I and a nursing aide at the senior daycare talked about diseases and such things, thus [...] and she said: "You should see if we do so-and-so" she said, and then she sort of told me what I should do to feel much better.

There were also seniors who said that they wanted to increase their participation in their care and treatment through information about earlier tests and blood samples, current treatment, and how to relieve pain conditions. They also wanted to know more about individual prognoses and what they could expect as they got older. Others wanted to learn more generally about dementia and cognitive impairment. The subcategory "Instrumental support" meant practical help, advice, and actions to facilitate contacts with other health care professionals who they could meet to discuss the participants' living conditions and personal needs for practical support and help in their homes. These home visits would also end their perceived loneliness and social isolation for a while. All participants reported that they missed, most of all, friends that they could talk to. One woman said:

Because for me, mental health means [...] that one has... eh...friends that one could talk to $[\ldots]$ and one does not have to sit alone and ruminate [...] When you are lonely $[\ldots]$ then you ruminate $[\ldots]$ and that is what I call mental illness! You know [...] mental health is for me [...] it's just

that I can talk with someone!

It was important that the seniors had opportunities to talk about their everyday lives and personal interests, such as literature, films, and theater. This would amuse them and lead to issues that they could talk about in a health dialogue. It was furthermore important to discuss other people's opinions and perceptions about "now and then", such as seniors' experiences from childhood and living conditions in their earlier days, along with opportunities to ask questions about how it was to be young and live in society today. There were also seniors who argued that dialogue would not promote mental health in itself, but social contacts would do. As one said: "I used to hobnob with people and [...] about this and that $[\ldots]$ but it always helps if you have a personal contact with someone". One woman repeatedly said that she appreciated personal dialogues but that she didn't want to be "too private" when she talked about her mental health with other people. She wanted to choose what she said (and how much) about herself in a health-promoting dialogue. Other seniors said that they wanted practical help getting in touch with someone at the hospital or health center who could help them relieve their pain: authorized people responsible for home help services, senior daycare, or support, so that they could get a disposition or a permanent stay in a nursing home where they could dine and talk with others. The emotional aspect of social support, "Emotional support", indicated an opportunity to express thoughts and emotions with someone else who could share the participating seniors' emotions and thoughts about their daily lives. These seniors said that the focus of a mental health dialogue should be on different personal losses, or fears about dementia and death expressed by themselves and their relatives. Furthermore, an individual dialogue about a senior's life situation was an opportunity to keep his or her mind and mental health "alert". All seniors reported that they had more and more existential thoughts and questions connected to their previous and present life experiences, together with expectations and fear about their own, and relatives' futures. Furthermore, a dialogue about the seniors' emotions and thoughts may relieve their perceived anxiety and angst. This could lead to feelings of relief and security about their life situations. Additionally, while the content of a dialogue should be about the seniors' personal emotions, it was difficult to talk about those, and explain those to other people. As one participant said: "I don't know what to say because it is not that easy to explain how and what one feels". The other seniors said that it was 
important that they had an opportunity to complain about what was bothering them or ruminate on their life situation. Another senior argued that she did not want to lament about her life when there were so many young people who died. There were also participants who reported that the content of the dialogue wasn't that important, even if they wanted to talk about something "positive" and "joyful", so that their mood could improve and make them feel happier. One participant said:

Well, it [an individual dialogue] keeps the mental health going and [...] the mood on the whole [...] Yes, but it's a relief if you have someone to talk to at all. It really doesn't matter what one talks about.

\section{Discussion}

The main finding in this study was the necessity of being seen as a unique individual by an accessible and competent person. The seniors with multimorbidity were missing someone to talk to about their mental health, and they needed partners who were accessible for health dialogues that could promote mental health. The participants missed friends and relatives to talk to, and they (crucially) lacked health care or social service providers for health-promoting dialogues - or general dialogues - that may promote their mental health.

The participants reported that, in order to disclose information about mental health to their health care or social service providers, certain criteria had to be met. Professional competence and communicative skills were important, as well as knowing each other well and creating a trusting, mutual, and continuous relationship. The seniors stressed the importance of talking about various issues related to their unique life situations, and they wanted a dialogue partner to be social, present, and somewhat personable. This could lead to an opportunity to talk about issues from the senior's own life perspective, being understood and confirmed as a unique person, and the ability to share thoughts and emotions with another person. The seniors also wanted instrumental support, such as more practical help with social contacts and help getting in touch with people who could provide them with informative support about their current diseases, as well as an opportunity to discuss and learn more about different topics. Some of them said that they would appreciate talking about professionals' own experiences of health care, treatment, diagnosis, and prognosis.

The participants perceived that health care and social services providers were often task-oriented and focused on practical matters instead of on dialogue with the senior.
The seniors perceived that social service and health care providers had a lack of time for a dialogue and were in a hurry, and that since the seniors' met many different health care and social service providers, it could be difficult to build a continuous and trusting relationship. The alliance of health care providers and the elderly is essential in the delivery of mental health services, ${ }^{29}$ and it can be strengthened by feeling that the relationship is mutual, ${ }^{30}$ person-centered, and authentic. ${ }^{31}$ A person-centered approach increases the chances of changing habits among patients, and this approach is associated with decreased utilization of health care services and lower costs..$^{32-34}$ The concept of person-centered care is described in the context of health-promoting dialogues, ${ }^{35}$ nursing, and community-based, long-term care for older adults living with chronic conditions. ${ }^{34,36}$

According to Svedberg et al, ${ }^{37}$ the essence of mental health promotion is empowerment, together with educational and practical support, provided by means of a good alliance. However, health care professionals have to provide practical support to patients in their actual life contexts, aimed at encouraging empowerment processes and reducing stigmatization..$^{37}$ To be given the opportunity to be involved and to take a more active part in different decisions about personal care, the health care system has to provide patient education and social support. ${ }^{38}$ Information about a disease may decrease insecurity and increase feelings of control, ${ }^{39}$ and help seniors with multimorbidity to cope with the consequences of diseases. ${ }^{40}$ Caregivers need to acknowledge that seniors' life situations involve living with uncertainty over time. ${ }^{41}$ Previously, seniors $(>75$ years old) reported poor understanding of their health and diseases. ${ }^{17}$ Bearing in mind that very old seniors seldom suffer from one disease, management programs addressing one disease seem not to be a very efficient way of providing care. ${ }^{21}$ Health care professionals have to provide adjusted information, based on concrete disorders, treatments, sex, ethnicity, and prognosis. ${ }^{31}$ Elderly patients may also need time to describe their everyday lives, to identify factors motivating the patient towards a change of lifestyle, ${ }^{42}$ and, if caregivers are in a hurry, they might not see seniors as individuals. ${ }^{43}$

One participant in our study was a man; the remaining six were women. Our findings did not indicate that there were any sex differences in the informants' experiences of what was important in dialogues that may promote mental health. In contrast, men may need more informative support than women, as there are sex differences in social support and coping among patients with different diseases. ${ }^{44,45}$ However, if the support is presented as information and 
advice, men would be more likely to take part in emotional support from nurses. ${ }^{45}$ Furthermore, emotional support and information about different topics may also help patients cope with the individual emotions that a certain disease may arouse - and they may then perceive this as emotional support. ${ }^{45}$ All seniors in our study said that they wanted to meet trustworthy people for a health dialogue. Clearly, meeting patients on their level, through confirmation and listening to them, is required to create a relationship with the patient that is built on trust. ${ }^{42}$ Additionally, examining the level of the senior's understanding is a necessary step in providing support; empowering seniors to provide self-care may be challenging. ${ }^{46}$ Nurses may use a cognitive and emotional tool, called "the visual art program", which focuses on the elderly person's knowledge and personal experience. ${ }^{47}$ These art dialogues may stimulate discussions on a variety of topics that positively shift seniors' perceptions of their life situations. ${ }^{47}$

The question remains as to whether these seniors' mental health would be promoted if they were provided support to lessen their perceived loneliness and offered dialogues about what was bothering them in their daily lives. First of all, loneliness has to be recognized as a common issue among seniors, if we are to prevent or alleviate it. ${ }^{48}$ Second, habits are deeply rooted and often influenced by individual preferences and values. ${ }^{35}$ Lifestyle counseling must therefore focus on more than facts and information, and should take the patient's attitudes, personal understandings, motivations, obstacles, self-efficacy, goals, readiness for change, and social support into account. ${ }^{49}$ However, social phobia may occur among seniors with depression, ${ }^{50}$ and this issue may be solved through telephone contacts. There were also seniors in this study who said that the forum or place for dialogues wasn't the most important factor, and social contacts through telephone were an option. This finding is in line with Alkema et al, ${ }^{20}$ who described how telephone contacts could be used in interventions that were related to preventive home care. Other seniors said that the content wasn't the most important factor in a dialogue that could promote mental health. Rather, it seemed that being present in the meeting was most important. This is in line with Nordgren et al, ${ }^{39}$ who argue that being present is more important than actions, when health care providers meet a patient in need of emotional support. Perhaps the most important aspect was that dialogue partners give the seniors self-confidence by confirming them as important and unique human beings, in whom someone else was still interested and who were asked about personal opinions, thoughts, and emotions. We may reflect if asking seniors "How are you doing?" could be used as an initial open question about perceived mental health, and if this could help health care professionals identify risk factors for mental health problems such as chronic pain, perceived loneliness, and social isolation.

For some participants in our study, it was important to meet people who were competent enough to support them with mental health-promoting activities and activities that would promote their overall health. So, maybe, the informants believed that general health promotion also promotes mental health. However, the goal of health promotion should be to improve mental, physical and social health, in combination with the prevention of mental, physical, and social ill-health. ${ }^{14}$ Consequently, mental health is the foundation for well-being, and there is "no health without mental health". 6 In caring for elderly patients, disease-oriented care must be replaced by person-oriented home care, over time. However, home care is a heterogeneous concept, with various objectives, contents, and expected outcomes. ${ }^{51}$ Mental health issues among community-dwelling seniors require better primary care, with resources that could meet these challenges. ${ }^{52}$ In Sweden, general practitioners and district nurses are the central actors in primary care. These health care professionals have a responsibility for both preventive and medical/nursing care for all age groups. ${ }^{53}$ Home visits are still an integral aspect of primary care and impose a considerable workload on many practices. Health care professionals consider house calls essential to the process of achieving a holistic view of patients and their special conditions. ${ }^{53}$ However, district nurses may be stuck between disease-oriented and health promotion work, ${ }^{14}$ and this may reflect the finding in our study that accessibility was considered an important factor by the participants.

We found that our sample technique was well suited to the aim and to the participants' abilities to talk about mental health. Downe-Wamboldt ${ }^{54}$ stated that content analysis has external validity as a goal, and that the sample technique is central to external validity. The findings in this study must be understood in the light of the fact that six of the seniors lived alone; this could influence the finding, as living alone has been found to affect the experience of loneliness among the very old. ${ }^{55}$ Two other limits of our study are in the number of participants, with only one male informant. Here, we followed our seniors from the first part of the research project. ${ }^{22}$ Our study may have benefitted from having additional interviewees, but it seems reasonable to believe that we have captured the main theme. The interviews appeared to be rich and substantial, in the depth and variation of reported experi- 
ences of general dialogues that may promote mental health. At the same time, trustworthiness in a qualitative study is gained more by the richness of each interview than by the sample size. ${ }^{56}$ Graneheim and Lundman ${ }^{24}$ argued that the concept of "credibility" arises when the researcher makes a decision on the focus of the study, selection of context, sample, or collection of data. The data was richer than expected, and the participants did not have the same difficulties talking about mental health as in our earlier study. ${ }^{22}$ Nevertheless, a text can never be reduced to one single meaning but just the most probable meaning, from a particular perspective. ${ }^{26}$ Thus, our findings should be considered as one possible interpretation of the participants' unique experiences. Krippendorff ${ }^{26}$ identified two forms of reliability: reproducibility and stability over time. Cavanagh ${ }^{57}$ stated that reproducibility is a type of intercoder reliability, and refers to the extent to which more than one coder independently classifies data in the same way. Therefore, all members of our research group were involved in the coding and categorizing of the findings in this study. This means that it is important for a high degree of reproducibility to exist in content analysis, as this would signify shared understanding of the data. The face validity of a category is the level to which it is a measurement of the construct it was designed (or was claimed) to measure. Content (or face) validity can only be determined by the judgments of experts in the area of research. It is also helpful to define categories that illustrate differences and similarities in the data ${ }^{54}$ Credibility is also about how well categories cover the data, and the similarities within and differences between categories. To enhance credibility, one must mention the value of dialogue among co-researchers, to agree on the way in which the data are labeled. ${ }^{24}$ In order to do that, we have provided examples of codes and emerged subcategories, categories, and the theme in Table 1.

In summary, the seniors with multimorbidity missed general dialogues with friends, relatives, and (especially) health care and social service providers. We may hypothesize that mental health could be improved through health dialogues with an accessible and competent health care professional, who could provide health dialogues that are person-centered and with a purpose to promote mental health. Further, meaningful social activities, tailored to the older individual's abilities, needs, and preferences should be considered when aiming to improve mental health among older people. ${ }^{58}$ The participants also described what aspects could promote mental health, such as social support and dialogues, in order to lessen social isolation. Additionally, social network and the perceived sense of social support and trust are amongst significant mental health-promoting factors among older adults; the overall effects of psychosocial interventions are small but promising. ${ }^{58}$ Despite that, community-dwelling seniors with multimorbidity together with perceived mental health problems and loneliness may carry a twofold stigma. These seniors may feel undesirable, because of mental health issues, and the social perceptions of lonely people may be unfavorable. With prolonged exposure to solitude, seniors with mental health problems may come to accept loneliness. An optimal level of care can be achieved through involvement, continuity, and by providing a healthpromoting dialogue based on seniors' needs and wishes, with the remembrance that general health promotion also may promote mental health. ${ }^{59}$ Further research is needed on how health care and social service providers can improve mental health among seniors with multiple chronic conditions.

\section{Relevance to clinical practice}

The implications of this study may be used as support and guidance for district nurses when developing their competence in health-promoting dialogues in relation to patients with multiple chronic conditions. This knowledge may also be important when planning for mental healthpromoting activities for community-dwelling seniors with multimorbidity.

\section{Acknowledgments}

We would like to thank the participants who shared their experiences with us, and Professor Ulla Hällgren Graneheim (Department of Nursing at Umeå University, Umeå, Sweden) for her valuable support when we started the analysis process.

The project was financially supported by National Health Care Science Postgraduate School, the Swedish Society of Medicine, and the Karolinska Institutet research foundation, Stockholm, Sweden.

\section{Disclosure}

The authors report no conflicts of interest in this work.

\section{References}

1. Martinsson G, Wiklund-Gustin L, Fagerberg I, Lindholm C. Mental disorders affect older persons in Sweden - a register-based study. Int $J$ Geriatr Psychiatry. 2011;26(3):277-283.

2. Berleen G. A Healthier Elderly Population in Sweden! Sandviken, Sweden: Swedish National Institute of Public Health; 2004. R 2004:2.

3. World Health Organization. Good health adds life to years: Global brief for World Health Day 2012. Geneva, Switzerland: World Health Organization; 2012 [cited December 16, 2013]. Available from: http:// www.who.int/ageing/publications/whd2012_global_brief/en/. 
4. Fortin M, Lapointe L, Hudon C, et al. Multimorbidity and quality of life in primary care: a systematic review. Health Qual Life Outcomes. 2004; $2: 51$

5. World Health Organization. Public health action for the prevention of suicide. A framework. Geneva, Switzerland: World Health Organization; 2012 [cited: December 16, 2013]. Available from: http://www.who.int/ mental_health/publications/prevention_suicide_2012/en/.

6. World Health Organization. Mental Health Promotion. Geneva, Switzerland: World Health Organization; 2010 [cited: December 16, 2013]. Available from: https://knowledgex.camh.net/policy_health/ mhpromotion/Pages/default.aspx.

7. Kalra G, Christodoulou G, Jenkins R, et al. Mental health promotion: guidance and strategies. Eur Psychiatry. 2012;27(2):81-86.

8. Swedish National Institute of Public Health. Healthy Ageing - A Challenge for Europe. Stockholm, Sweden: Swedish National Institute of Public Health; 2006. R 2006:29.

9. World Health Organization. Active ageing: towards age-friendly primary health care. Geneva, Switzerland: World Health Organization; 2004 [cited December 16, 2013]. Available from: http://whqlibdoc.who. int/publications/2004/9241592184.pdf.

10. Lyness JM, Yu Q, Tang W, Tu X, Conwell Y. Risks for depression onset in primary care elderly patients: potential targets for preventive interventions. Am J Psychiatry. 2009;166(12):1375-1383.

11. Bonnewyn A, Katona C, Bruffaerts R, et al. Pain and depression in older people: comorbidity and patterns of help seeking. JAffect Disord. 2009;117(3):193-196.

12. Perissinotto CM, Stijacic Cenzer I, Covinsky KE. Loneliness in older persons. A predictor of functional decline and death. Arch Intern Med. 2012;172(14):1078-1083.

13. Valderas J, Starfield B, Sibbald B, Salisbury C, Roland M. Defining comorbidity: implications for the understanding health and health services. Ann Fam Med. 2009;7(4):357-363.

14. Wilhelmsson S, Lindberg M. Health promotion: facilitators and barriers perceived by district nurses. Int J Nurs Pract. 2009;15(3):156-163.

15. Stuck AE, Egger M, Hammer A, Minder CE, Beck JC. Home visits to prevent nursing home admissions and functional decline in elderly people: systematic review and meta-regression analysis. JAMA. 2002;287(8):1022-1028.

16. Thelie G, Kruschinski C, Buck M, Müller CA, Hummers-Pradier E. Home visits - central to primary care, tradition or an obligation? A qualitative study. BMC Fam Pract. 2011;12:24.

17. Sherman H, Forsberg C, Karp A, Törnkvist L. The 75-year old persons' self-reported health conditions: a knowledge base in field of preventive home visits. J Clin Nurs. 2012;21(21-22):3170-3182.

18. Johansson B, Malmberg B. Gerontology in Sweden. A research and institutional perspective. Contemp Gerontol. 2004;11(2):55-59.

19. Socialtjänstlag [Social Services Act]. SFS 2001: 453. Sweden. 2001. Swedish.

20. Alkema GE, Shannon GR, Wilber KH. Using interagency collaboration to serve older adults with chronic care needs: the Care Advocate Program. Fam Community Health. 2003;26(9):221-229.

21. Hallberg IR, Kristensson J. Preventive home care of frail older people: a review of recent case management studies. J Clin Nurs. 2004;13(6B): $112-120$.

22. Grundberg Å, Ebbeskog B, Dahlgren MA, Religa D. How communitydwelling seniors with multimorbidity conceive the concept of mental health and factors that may influence it: a phenomenographic study. Int J Qual Stud Health Well-being. 2012;7:1-13.

23. McEvoy P, Barnes P. Using the chronic care model to tackle depression among older adults who have long-term physical conditions. J Psychiatr Ment Health Nurs. 2007;14(3):233-238.

24. Graneheim UH, Lundman B. Qualitative content analysis in nursing research: concepts, procedures and measures to achieve trustworthiness. Nurse Educ Today. 2004;24(2):105-112.

25. Kvale S, Brinkman S. Den kvalitativa forskningsintervjun [The qualitative research interview]. 2nd ed. Lund, Sweden: Studentlitteratur; 2009.
26. Krippendorff K. Content Analysis. An Introduction to its Methodology. 2nd ed. Thousand Oaks: CA: Sage Publications; 2004.

27. Dahlgren L, Emmelin M, Winkvist A. Qualitative Methodology for International Health. 2nd ed. Umeå, Sweden: Epidemiology and Public Health Sciences, Department of Public Health and Clinical Medicine, Umeå University; 2007.

28. Patton MQ. Qualitative Research and Evaluation Methods. 3rd ed. Thousand Oaks, CA: Sage Publications; 2002.

29. Priebe $\mathrm{S}, \mathrm{McCabe} \mathrm{R}$. The therapeutic relationship in psychiatric settings. Acta Psychiatr Scand Suppl. 2006;(429):69-72.

30. Hedelin B, Jonsson I. Mutuality as background music in women's lived experience of mental health and depression. J Psychiatr Ment Health Nurs. 2003;10(3):317-322.

31. McCabe C. Nurse-patient communication: an exploration of patients' experiences. J Clin Nurs. 2004;13(1):41-49.

32. Bertakis KD, Azari R. Patient-centered care is associated with decreased health care utilization. J Am Board Fam Med. 2001;24(3):229-239.

33. Ekman I, Wolf A, Olsson LE, et al. Effects of person-centred care in patients with chronic heart failure: the PCC-HF study. Eur Heart J. 2012;33(9):1112-1119.

34. Ruggiano N, Edvardsson D. Person-centeredness in home- and community-based long-term care: current challenges and new directions. Soc Work Health Care. 2013;52(9):846-861.

35. Hörnsten Å, Lindahl K, Persson K, Edvardsson K. Strategies in health-promoting dialogues - primary healthcare nurses'perspectives - a qualitative study. Scand J Caring Sci. April 17, 2013 [cited: December 16, 2013]. [Epub ahead of print]. Available from: http://onlinelibrary.wiley. com/doi/10.1111/scs.12045.

36. Mitchell GJ, Cross N, Wilson M, et al. Complexity and health coaching: synergies in nursing. Nurs Res Pract. 2013;2013:238620.

37. Svedberg P, Arvidsson B, Svensson B, Hansson L. Psychometric characteristics of a self-report questionnaire (HPIQ) focusing on health promotion intervention in mental health services. Int J Ment Health Nurs. 2008;17(3):171-179.

38. Rosenqvist U. Patient education - new trends in Sweden. Patient Educ Couns. 2001;44(1):55-58.

39. Nordgren L, Asp M, Fagerberg I. Support as experienced by men living with heart failure in middle age: a phenomenological study. Int J Nurs Stud. 2008;45(9):1344-1354.

40. Edmonds P, Vivat B, Burman R, Silber E, Higginson I. Loss and change: experiences of people severely affected by multiple sclerosis. Palliat Med. 2007;21(2):101-107.

41. Breitholtz A, Snellman I, Fagerberg I. Living with uncertainty: older persons' lived experience of making independent decisions over time. Nurs Res Pract. 2013;2013:403717. Epub March 7, 2013.

42. Eriksson I, Nilsson K. Preconditions needed for establishing a trusting relationship during health counselling - an interview study. J Clin Nurs. 2008;17(17):2352-2359.

43. Breitholtz A, Snellman I, Fagerberg I. Older people's dependence on caregivers' help in their own homes and their lived experiences of their opportunity to make independent decisions. Int J Older People Nurs. 2012;8(2):139-148.

44. Kristofferzon ML, Löfmark R, Carlsson M. Myocardial infarction: gender differences in coping and social support. JAdv Nurs. 2003;44(4): 360-374.

45. Clarke SA, Booth L, Velikova G, Hewison J. Social support: gender differences in cancer patients in the United Kingdom. Cancer Nurs. 2006;29(1):66-72.

46. Hadert A, Rodham K. The invisible reality of arthritis: a qualitative analysis of an online message board. Musculoskeletal Care. 2008;6(3): 181-196.

47. Wikström BM. Visual art dialogues with elderly persons: effects on perceived life situation. J Nurs Manag. 2000;8(1):31-37.

48. Taube E, Kristensson J, Midlöv P, Holst G, Jakobsson U. Loneliness among older people: results from the Swedish National Study on Aging and Care - Blekinge. Open Geriatr Med J. 2013;6(1):1-10. 
49. Schäfer Elinder L, Faskunger J. Fysisk aktivitet och folkhälsa [Physical activity and public health]. Stockholm, Sweden: Swedish National Institute of Public Health; 2006. R 2006:13. Available from: http:// www.fhi.se/PageFiles/3358/R200613_Fysisk_aktivitet_0701.pdf.

50. Karlsson T. Social phobia among the elderly [dissertation]. Gothenburg, Sweden: University of Gothenburg; 2013.

51. Thomé B, Dykes AK, Hallberg IR. Home care with regard to definition, care recipients, content and outcome: systematic literature review. J Clin Nurs. 2003;12(6):860-872.

52. Starfield B. Challenges to primary care from co- and multi-morbidity. Prim Health Care Res Dev. 2011;12(1):1-2.

53. Strandberg EL, Ovhed I, Borgquist L, Wilhelmsson S. The perceived meaning of a (w)holistic view among general practitioners and district nurses in Swedish primary care: a qualitative study. BMC Fam Pract 2007;8:8.
54. Downe-Wamboldt B. Content analysis: method, applications, and issues. Health Care Women Int. 1992;13(3):313-321.

55. Graneheim UH, Lundman B. Experiences of loneliness among the very old: the Umeå 85 + project. Aging Ment Health . 2010;14(4):433-438.

56. Sandelowski M. Sample size in qualitative research. Res Nurs Health. 1995;18(2):179-183.

57. Cavanagh S. Content analysis: concepts, methods and applications. Nurse Res. 1997;4(3):5-16.

58. Forsman AK, Nordmyr J, Wahlbeck K. Psychosocial interventions for the promotion of mental health and the prevention of depression among older adults. Health Promot Int. 2011;26 Suppl 1:i85-i107.

59. Kiraly JS. Mental health promotion for seniors. BCMJ. 2011;53(7): 336-340.
Journal of Multidisciplinary Healthcare

\section{Publish your work in this journal}

The Journal of Multidisciplinary Healthcare is an international, peerreviewed open-access journal that aims to represent and publish research in healthcare areas delivered by practitioners of different disciplines. This includes studies and reviews conducted by multidisciplinary teams as well as research which evaluates the results or conduct of such teams or

\section{Dovepress}

healthcare processes in general. The journal covers a wide range of areas and welcomes submission from practitioners at all levels, from all over the world. The manuscript management system is completely online and includes a very quick and fair peer-review system. Visit http://www.dovepress.com/testimonials.php to read real quotes from published authors.

Submit your manuscript here: http://www.dovepress.com/journal-of-multidisciplinary-healthcare-journal 